\title{
ADRENAL MEDULLARY INSUFFICIENCY IN SEVERE THERMAL BURN *
}

\author{
By McC. GOODALL and B. W. HAYNES, Jk. \\ (From the Memorial Research Center and Hospital, University of Tennessee, Knoxville, Tenn., \\ and the Department of Surgery, Medical College of Virginia, Richmond, Va.)
}

(Submitted for publication March 18, 1960; accepted August 17, 1960)

Although adrenal medullary insufficiency is occasionally seen in Addison's disease and under certain experimental conditions (1-3), it has not been described in man as a result of thermal burns or of other clinical states.

The normal human adrenal contains 412 to 633 $\mu \mathrm{g}$ of adrenaline and 37 to $123 \mu \mathrm{g}$ of noradrenaline. These results compare favorably with those of von Euler, Franksson and Hellström (4). Adrenaline is the principal hormone of the adrenal medulla (4-6) and is released in increased amounts under various stressful situations, i.e., thermal burns ( 7$)$, muscular exercise (8), centrifugation (9), and trauma (10). Noradrenaline, although also found in the human adrenal medulla $(4,6)$, is primarily derived from the sympathetic nerves (11-16). Noradrenaline is the neurohormone of the sympathetic nerves and is released as such at the adrenergic nerve endings $(12,14,16)$. Like adrenaline, noradrenaline is also liberated in increased amounts under various stressful situations (7-10).

Both of these hormones, as well as their metabolic products (17-21), are excreted in the urine in amounts which parallel the sympathetic nerve and adrenal medullary activity (6). Normal young adult males excrete approximately 10 to $25 \mu \mathrm{g}$ of adrenaline and 25 to $45 \mu \mathrm{g}$ of noradrenaline per 24 hours $(7,22)$. It is further known that the adrenal gland normally synthesizes adrenaline with such rapidity (23-25) that only under unusual circumstances can the adrenal medulla be depleted of its adrenaline supply $(1,3)$. It has been shown that most patients who survive severe thermal burns excrete daily large amounts of adrenaline and noradrenaline, and that this elevated rate of excretion continues for weeks without any recognizable failure in the adrenal gland's ability to produce adrenaline (7). However, of the burned patients who died, approximately two-

\footnotetext{
* Supported by U. S. Army Contract DA-49-007-MD-
} 1018 . thirds showed a markedly depressed adrenaline output at the time of death. The experiments herein described attempt to correlate this low adrenaline output with a low adrenaline content of the adrenal gland and further, to evaluate this finding in terms of an acute adrenal medullary insufficiency.

\section{Urine \\ METHOD}

A. General. Daily 24-hour urines were collected and bioassayed for adrenaline and noradrenaline.

$B$. Preparation of urine extract. The procedure was adopted from von Euler and Hellner (22). The urine was hydrolyzed and the adrenaline and noradrenaline selectively adsorbed on aluminum hydroxide and filtered. The precipitate was washed and redissolved with $2 \mathrm{~N}$ $\mathrm{H}_{2} \mathrm{SO}_{4}$. The remaining salts were precipitated out by mixing the extract with alcohol and acetone. The filtrate was concentrated in vacuo.

C. Biological assay of urine. This procedure has been previously described $(4,5,7,26)$. In brief, the cat's blood pressure, which is sensitive to noradrenaline, is used in conjunction with the fowl's rectal cecum, which is sensitive to adrenaline.

The cat's blood pressure was recorded from the carotid artery and injections of adrenaline, noradrenaline and urinary extract were made into the femoral vein.

The fowl's rectal cecum was suspended in a water bath containing Tyrode's solution at $39^{\circ} \mathrm{C}$. Through the Tyrode solution, 6.5 per cent of $\mathrm{CO}_{2}$ in oxygen was bubbled. Injections of adrenaline, noradrenaline and urinary extract were made into the bath and the degree of cecal relaxation was recorded on a kymograph.

D. Computation of results. Having determined the activity ratio for adrenaline and noradrenaline on the cat's blood pressure and on the hen's rectal cecum, and the activity of the unknown urinary extract in terms of $l$-noradrenaline, it is possible to calculate the relative amounts of adrenaline and noradrenaline in the urinary extract $(4,5,7,26)$.

\section{Adrenal gland}

A. General. The adrenal gland was removed 1 to 7 hours after death, weighed, and placed in 5 per cent trichloroacetic acid.

B. Preparation of adrenal extract. The procedure used for preparing the extract is rather similar to that described under "urine extract." However, as a prelimi- 
TABLE I

Urinary adrenaline and noradrenaline of burned patients who died with low (Group A) and high (Group B) adrenaline output

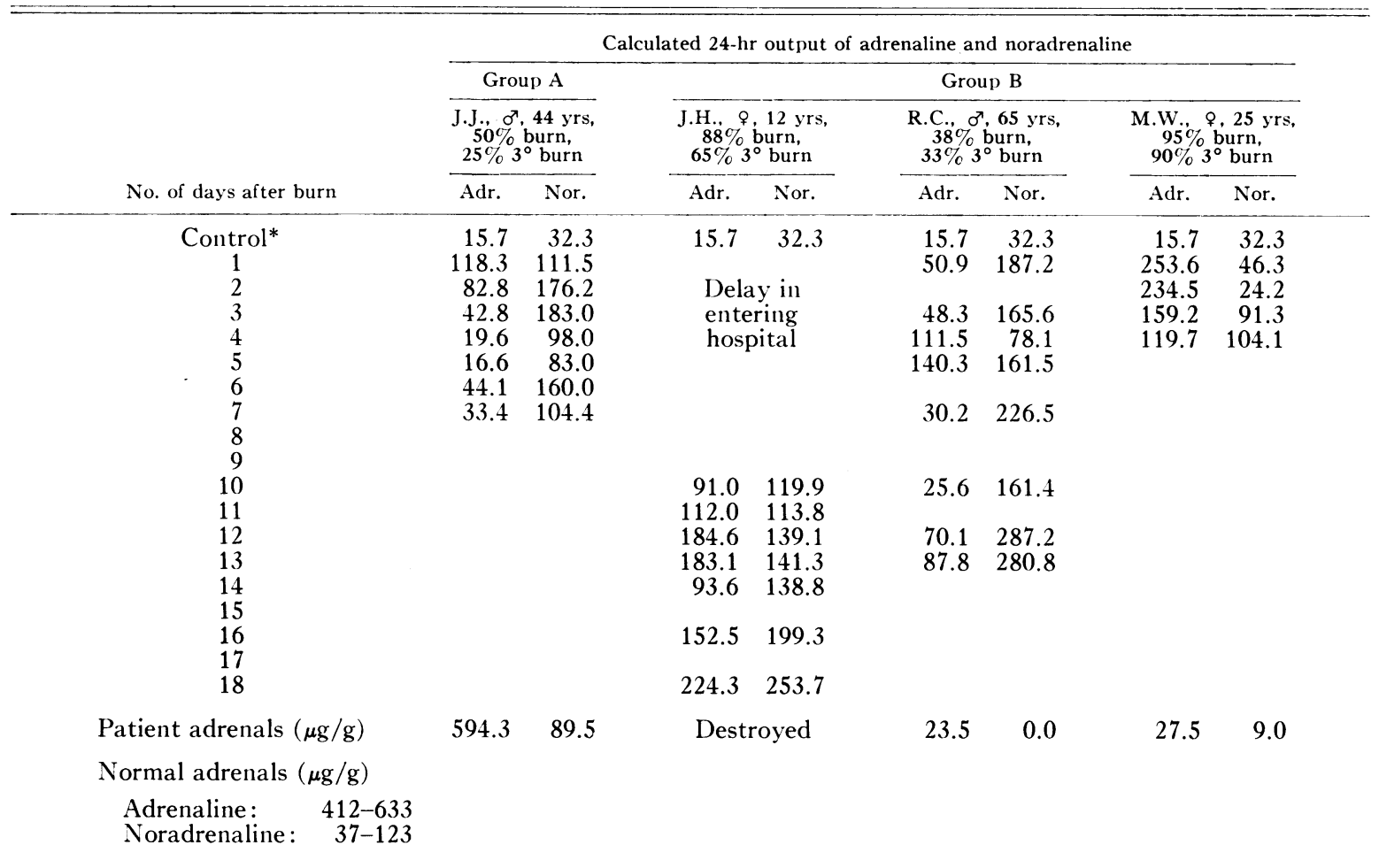

* Control represents average normal 24-hour urinary output of adult males.

nary step, the adrenal gland is homogenized in trichloroacetic acid and the adrenaline and noradrenaline are then selectively adsorbed on aluminum hydroxide and subsequently eluted.

C. Colorimetric assay. Because of the large quantities of adrenaline normally found in the human adrenal gland, the colorimetric method of von Euler and Hamberg (27) was used. This method is based upon the different oxidation velocity of adrenaline versus noradrenaline with iodine at $\mathrm{pH} 4$ and $\mathrm{pH} 6$; adrenaline is completely oxidized in 1.5 minutes at $\mathrm{pH} \mathrm{4}$, while only 10 per cent of noradrenaline is oxidized at this $\mathrm{pH}$. At $\mathrm{pH}$, both amines show complete oxidation.

\section{Rate of adrenaline deterioration following death}

In order to determine the amount of deterioration of adrenaline that might occur in the adrenal gland following death, 12 rabbits were killed and maintained at room temperature. Then, at hourly intervals for 12 hours following death, the adrenals of one rabbit were removed and assayed for adrenaline and noradrenaline, thereby affording an hourly deterioration picture of adrenaline in the adrenal gland. The results of these experiments showed that no appreciable destruction of either adrenaline or noradrenaline took place within a 10 hour period following death but, thereafter, there was a significant decline in both of these hormones. These findings would seem to indicate that as long as the adrenal glands were removed from the patient within 10 hours after death, very little destruction of adrenaline would be expected.

\section{RESULTS}

A total of 14 severely burned patients was followed, all of whom died. In each patient, the daily 24-hour urinary output of adrenaline and noradrenaline was determined and at death, correlated to the adrenaline content of the adrenal gland.

One of the 14 patients (J.J.) showed at first a markedly elevated adrenaline output, but this gradually declined until, at the time of death, the output was approximately normal but low relative to the degree of stress. The adrenaline content of the adrenal gland of this patient was normal (Table I, Group A).

Two other patients (R.C. and M.W.) showed a high output of adrenaline throughout the burn period. The adrenaline content of their adrenal glands was greatly reduced (Table I, Group B).

The remaining 10 patients, i.e., 71.5 per cent of 
all the burnerl patients, showed at the time of death a low output of adrenaline which was subnormal for the stress imposed by the burn. The adrenaline content of the adrenal gland was greatly reduced and in some instances (E.B. and H.T.) approached zero. However, it should be noted that during the first 3 or 4 days after the burn, most of the patients in this group excreted large quantities of adrenaline, but this gradually decreased so that at the time of death the output was subnormal (Table II).

The normal urinary levels of adrenaline and noradrenaline were determined from the 24-hour specimens of normal adult males varying in age from 20 to 40 years. Calculated on the basis of 24-hour output, the average quantity of adrenaline excreted was $15.7 \mu \mathrm{g}$, and of noradrenaline 32.3 $\mu \mathrm{g}$. These results were used as controls and are similar to the normal output as determined by von Euler and Hellner (22).
In normal suljects, the urinary output of adrenaline and noradrenaline is independent of the urine volume. This would seem also to hold true in these burn patients, although some of them showed signs of acute renal failure with oliguria, elevated creatinine excretion, and an elevated blood urea nitrogen (BUN). However, as long as the patient's 24-hour urinary output exceeded $150 \mathrm{ml}$, the renal failure apparently had little or no effect upon the urinary output of adrenaline and noradrenaline. This can be seen from Patient W.V. who on the first day after burn showed a urinary output of $220 \mathrm{ml}$, and on the terminal day an output of $173 \mathrm{ml}$; however, the urinary output of adrenaline for these days was 658.2 and $19.1 \mu \mathrm{g}$, respectively (Table II). Also, there were several patients (J.J., H.T. and J.L.) who terminally showed a low adrenaline output but a urine output in excess of $680 \mathrm{ml}$ per 24 hours and a BUN of 16 to $92 \mathrm{mg}$ per $100 \mathrm{ml}$.

TABLE II

Urinary adrenaline and noradrenaline of burned patients who died with low adrenaline output and low adrenaline content of the adrenal gland

\begin{tabular}{|c|c|c|c|c|c|c|c|c|c|c|}
\hline \multirow[b]{3}{*}{ No. of days after burn } & \multicolumn{10}{|c|}{ Calculated 24-hr output of adrenaline and noradrenaline } \\
\hline & \multicolumn{2}{|c|}{$\begin{array}{l}\text { J.W. } 0^{\circ}, 32 \text { yrs, } \\
81 \% \text { burn, } \\
50 \% 3^{\circ} \text { burn }\end{array}$} & \multicolumn{2}{|c|}{$\begin{array}{l}\text { R.T. } 0^{7}, 27 \text { yrs, } \\
60 \% \text { burn, } \\
50 \% 3^{\circ} \text { burn }\end{array}$} & \multicolumn{2}{|c|}{$\begin{array}{l}\text { A.W., } \sigma^{7}, 19 \text { yrs, } \\
85 \% \text { burn, } \\
59 \% 3^{\circ} \text { burn }\end{array}$} & \multicolumn{2}{|c|}{$\begin{array}{c}\text { E.T.L. } \% \text {, } 49 \text { yrs, } \\
47 \% \text { burn, } \\
35 \% 3^{\circ} \text { burn }\end{array}$} & \multicolumn{2}{|c|}{$\begin{array}{c}\text { J.M... } 0^{\sigma^{7}} 43 \text { yrs, } \\
75 \% \text { burn, } \\
75 \% 3^{\circ} \text { burn }\end{array}$} \\
\hline & Adr. & Nor. & Adr. & Nor. & Adr. & Nor. & Adr. & Nor. & Adr. & Nor. \\
\hline $\begin{array}{c}\text { Control* } \\
1 \\
2 \\
3 \\
4 \\
5 \\
6 \\
7 \\
8 \\
9 \\
10\end{array}$ & $\begin{array}{r}15.7 \\
125.3 \\
62.1 \\
54.6 \\
18.8 \\
3.7\end{array}$ & $\begin{array}{r}32.3 \\
303.4 \\
230.4 \\
374.9 \\
152.5 \\
30.0\end{array}$ & $\begin{array}{r}15.7 \\
42.0 \\
58.1 \\
62.9 \\
63.6 \\
78.3 \\
40.8 \\
80.8 \\
49.1 \\
19.9 \\
1.9\end{array}$ & $\begin{array}{r}32.3 \\
274.9 \\
313.1 \\
322.6 \\
302.4 \\
213.9 \\
249.9 \\
158.1 \\
172.8 \\
62.6 \\
7.5\end{array}$ & $\begin{array}{r}15.7 \\
257.1 \\
54.8 \\
30.4\end{array}$ & $\begin{array}{r}32.3 \\
113.9 \\
229.0 \\
71.3\end{array}$ & $\begin{array}{r}15.7 \\
34.0 \\
10.1 \\
3.1 \\
7.5\end{array}$ & $\begin{array}{r}32.2 \\
20.6 \\
22.6 \\
22.9 \\
5.6\end{array}$ & $\begin{array}{r}15.7 \\
394.0 \\
142.1 \\
32.9 \\
210.1 \\
74.0 \\
67.3 \\
33.0 \\
43.0 \\
79.6 \\
13.5\end{array}$ & $\begin{array}{r}32.3 \\
121.6 \\
226.6 \\
237.2 \\
280.1 \\
323.5 \\
117.7 \\
152.7 \\
184.2 \\
77.9 \\
95.2\end{array}$ \\
\hline \multirow[t]{3}{*}{ Patient adrenals $(\mu \mathrm{g} / \mathrm{g})$} & 150.8 & 49.9 & 141.9 & 38.6 & 118.7 & 44.3 & 294.0 & 112.8 & 191.0 & 36.7 \\
\hline & \multicolumn{2}{|c|}{$\begin{array}{c}\text { W.V., } \sigma^{\top}, 29 \text { yrs, } \\
90 \% \text { burn, } \\
50 \% 3^{\circ} \text { burn }\end{array}$} & \multicolumn{2}{|c|}{$\begin{array}{c}\text { F.T. }{ }^{\circ} \text {. } 51 \text { yrs, } \\
85 \% \text { burn, } \\
85 \% 3^{\circ} \text { burn }\end{array}$} & \multicolumn{2}{|c|}{$\begin{array}{l}\text { J.L.. } \sigma^{\top}, 39 \text { yrs, } \\
94 \% \text { burn, } \\
70 \% 3^{\circ} \text { burn }\end{array}$} & \multicolumn{2}{|c|}{$\begin{array}{l}\text { E. B. }{ }^{\circ} \%^{\circ} 47 \text { yrs, } \\
50 \% 3^{\circ} \text { burn, } \\
\end{array}$} & \multicolumn{2}{|c|}{$\begin{array}{c}\text { H.T. T. } \sigma^{\top}, 35 \text { yrs, } \\
83 \% \text { burn, } \\
82 \% 3^{\circ} \text { burn }\end{array}$} \\
\hline & Adr. & Nor. & Adr. & Nor. & Adr. & Nor. & Adr. & Nor. & Adr. & Nor. \\
\hline $\begin{array}{c}\text { Control* } \\
1 \\
2 \\
2 \\
4 \\
5\end{array}$ & $\begin{array}{r}15.7 \\
658.2 \\
74.8 \\
47.9 \\
19.1\end{array}$ & $\begin{array}{r}32.3 \\
51.9 \\
130.8 \\
73.2\end{array}$ & $\begin{array}{l}15.7 \\
13.0\end{array}$ & $\begin{array}{l}32.3 \\
22.0\end{array}$ & $\begin{array}{l}15.7 \\
41.5 \\
24.6 \\
19.4 \\
20.2 \\
12.9\end{array}$ & $\begin{array}{r}32.3 \\
54.1 \\
71.4 \\
108.2 \\
73.9 \\
22.6\end{array}$ & $\begin{array}{r}15.7 \\
48.9 \\
11.9 \\
8.4 \\
3.7\end{array}$ & $\begin{array}{l}32.3 \\
71.4 \\
74.2 \\
66.3 \\
47.6\end{array}$ & $\begin{array}{r}15.7 \\
52.5 \\
152.9 \\
46.4\end{array}$ & $\begin{array}{r}32.3 \\
14.0 \\
274.4 \\
126.7\end{array}$ \\
\hline Patient adrenals $(\mu \mathrm{g} / \mathrm{g})$ & 63.9 & 46.0 & 86.8 & 179.0 & 50.8 & 18.0 & 8.5 & 12.9 & 7.8 & 13.5 \\
\hline \multicolumn{11}{|l|}{ Normal adrenals $(\mu \mathrm{g} / \mathrm{g})$} \\
\hline $\begin{array}{lr}\text { Adrenaline: } & 412-633 \\
\text { Noradrenaline: } & 37-123\end{array}$ & & & & & & & & & & \\
\hline
\end{tabular}

* Represents average normal 24-hour urinary output of adult males. 

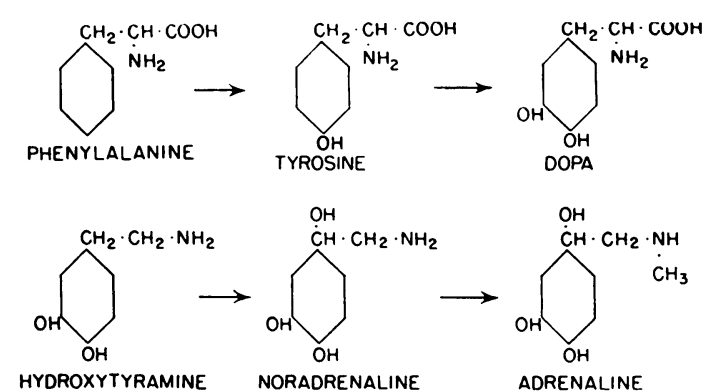

Fig. 1. Biosynthetic PATHWAy to THE FORMATION OF ADRENALINE AND NORADRENALINE.

DISCUSSION

From the results described in Tables I and II. it is apparent that these burned patients at the time of death fall into three distinct groups: Group A, low to normal adrenaline output with normal adrenaline content of the adrenal gland; Group B, high adrenaline output with a low adrenaline content of the adrenal gland; and Group C, low adrenaline output with a low adrenaline content of the adrenal gland. In terms of supply and demand for adrenaline, these three groups would appear to be gradations of the same conditions, that is, the supply or synthesis of adrenaline did or did not keep up with the demand for and release of this hormone. The demand is represented by the physiological "stress" of the burn.

The low to normal adrenaline output with normal adrenals, as seen in Table I, Group A, represents those patients in whom the severity of burn was considerably less than that observed in Table II, Group C. The demand for and release of adrenaline was probably not of sufficient magnitude to deplete the adrenals of adrenaline. This explanation seems especially logical since the resynthesis of adrenaline is normally quite rapid (23-25).

It would then follow that if the demand (release) were exceptionally great, the aclrenals could be partially or totally depleted of their adrenaline storage. Such a condition has been demonstrated experimentally by administering insulin (1) and acetylcholine (3). In such a situation where demand (release) is especially great, the urinary output of adrenaline would remain elevated only as long as the reserve supply was intact. Once the storage of adrenaline is depleted, the urinary output of adrenaline would be governed by the rate of adrenaline resynthesis. Since resynthesis is normally rapid (23-25), one would expect a fairly high urinary output of adrenaline. Patients in Group B, Table I, showing a high urinary output of adrenaline and low content of adrenaline in the adrenal gland, would apparently represent such a situation.

The third group (Group C) of patients, which represents 71.5 per cent of all the burned patients who died, showed a low urinary adrenaline and low adrenaline content of the adrenal gland (Table II). In general, these patients at first were capable of producing large quantities of adrenaline, as is seen by their initial high output. However, the adrenal medulla was apparently unable to synthesize adrenaline rapidly enough and certainly not at a rate commensurate with demand; consequently, the adrenal gland was largely depleted of its adrenaline, leading to a terminal picture of low urinary adrenaline and a low adrenaline content of the adrenal gland; that is, an acute medullary insufficiency developed.

Why an acute adrenal medullary insufficiency develops is difficult to say. However, it would appear that this insufficiency is typical to these particular burn patients and represents an inherent failure on the part of their medulla. This seems especially plausible since the normal adrenal medullary tissue can synthesize large quantities of adrenaline for long periods of time, as is characteristically seen in severely burned patients who survive $(7)$. Although the normal medulla rapidly synthesizes adrenaline, the extent of this synthesis is at least in part dependent upon the inflow of the necessary adrenaline precursors. Since the biosynthetic pathway for adrenaline formation is through phenylalanine, tyrosine, dopa, hydroxytyramine and noradrenaline (28-30) (Figure 1) and since the adrenal medulla can synthesize adrenaline from tyrosine (28), dopa (28), hydroxytyramine (28), or noradrenaline (31), a deficiency in any one of these precursors could ultimately lead to a deficit in adrenaline formation. It is further known that hepatic damage commonly occurs in severely burned patients and, since the metabolism of phenylalanine $(32,33)$ and tyrosine $(34,35)$ is so closely linked with liver function, it would then seem logical that hepatic failure might indirectly also play a part in the failure of the adrenal medulla to synthesize adrenaline. Finally, after prolonged periods of infusion which often occur in treating burned patients, an inade- 
quate diet itself might then possibly play a contributory role in the adrenaline deficit. Studies are currently under way to determine the therapeutic use of various adrenaline precursors in severe burns.

In evaluating the etiology of adrenal medullary insufficiency following thermal burn, one must also consider the possible role of the sympathetic nervous system in adrenaline synthesis. Since the adrenal medulla in the absence of sympathetic innervation readily synthesizes adrenaline (28), it would appear that the sympathetic nerves, per se, have little or no direct control over adrenaline synthesis. Therefore, the premise that the medullary failure might originate in the sympathetic nervous system or higher centers seems unreasonable. On the other hand, the sympathetic nerves to the adrenal medulla are intimately related to the release of adrenaline $(6,36)$.

To use a very crude analogy as a means of recapitulation, the adrenal medulla resembles a reservoir in which the inflow is represented by resynthesis of adrenaline and the outflow by the demand for and release of adrenaline. If the demand (release) exceeds the rate of resynthesis, the reservoir is depleted and the output is then governed entirely by resynthesis. If the resynthesis is rapid, then the demand is fulfilled and the reservoir remains full. In some patients the inflow, or rate of resynthesis, is apparently inadequate to meet the heavy demands imposed by the severe "stress" of burn and, consequently, the adrenals are emptied of their adrenaline storage. This latter picture would, therefore, represent an acute medullary insufficiency since the failure is ultimately in the rate of resynthesis. In view of adrenaline's important metabolic $(37-40)$, cardiac $(38,41-43)$, and vascular action (44-46), this insufficiency is more than likely an important contributory factor in the death of the patient.

Although this paper has devoted its attention strictly to acute adrenal medullary insufficiency in severe thermal burns, it would certainly seem that a similar picture could develop in other severely stressful situations such as those which might be seen after extensive surgery, severe trauma, necrotizing pancreatitis, extensive myocardial infarction, meningococcal septicemia and so forth, and, as has been recently shown, in $\mathrm{X}$-irradiation (47).

\section{SUMMARY}

1. The urine and adrenals of 14 burned patients who died were assayed for adrenaline and noradrenaline.

2. Approximately two-thirds of these burned patients showed at death a subnormal adrenaline output and a low adrenaline content of the adrenal gland, a condition commensurate with acute adrenal medullary insufficiency.

3. The possible mechanism of this adrenal medullary insufficiency was discussed.

\section{REFERENCES}

1. Hökfelt, B. Noradrenaline and adrenaline in mammalian tissues. Distribution under normal and pathological conditions with special reference to the endocrine system. Acta physiol. scand. 1951, 25, suppl. 92.

2. Udenfriend, S., Cooper, J. R., Clark, C. T., and Baer, J. E. Rate of turnover of epinephrine in the adrenal medulla. Science 1953, 117, 663.

3. Butterworth, K. R., and Mann, M. The adrenaline and noradrenaline content of the adrenal gland of the cat following depletion by acetylcholine. Brit. J. Pharmacol. 1957, 12, 415.

4. von Euler, U. S., Franksson, C., and Hellström, J. Adrenaline and noradrenaline content of surgically removed human suprarenal glands. Acta physiol. scand. $1954,31,6$.

5. Goodall, McC. Studies of adrenaline and noradrenaline in mammalian heart and suprarenals. Acta physiol. scand. 1951, 24, suppl. 85 .

6. von Euler, U. S. Noradrenaline. Chemistry, Physiology, Pharmacology, and Clinical Aspects. Springfield, Ill., Charles C Thomas, 1956.

7. Goodall, McC., Stone, C., and Haynes, B. W., Jr. Urinary output of adrenaline and noradrenaline in severe thermal burns. Ann. Surg. 1957, 145, 479.

8. von Euler, U. S., and Hellner, S. Excretion of noradrenaline and adrenaline in muscular work. Acta physiol. scand. 1952, 26, 183.

9. Goodall, McC., and Meehan, J. P. Correlation of ' $\mathrm{g}$ ' tolerance to urinary adrenaline and noradrenaline (abstract). Amer. J. Physiol 1956, 187, 601.

10. Franksson, C., Gemzell, C. A., and von Euler, U. S. Cortical and medullary adrenal activity in surgical and allied conditions. J. clin. Endocr. 1954, 14, 608.

11. von Euler, U. S. Identification of the sympathomimetic ergone in adrenergic nerves of cattle (Sympathin N) with laevo-noradrenaline. Acta physiol. scand. 1948, 16, 63.

12. Goodall, McC., and Kirshner, N. Biosynthesis of epinephrine and norepinephrine by sympathetic nerves and ganglia. Circulation 1958, 17, 366.

13. von Euler, U. S. The nature of adrenergic nerve mediators. Pharmacol. Rev. 1951, 3, 247. 
14. von Euler, U. S., and Purkhold, A. Effect of sympathetic denervation on the noradrenaline and adrenaline content of the spleen, kidney, and salivary glands in the sheep. Acta physiol. scand. 1951, 24, 212.

15. von Euler, U. S., Franksson, C., and Hellström, J. Adrenaline and noradrenaline output in urine after unilateral and bilateral adrenalectomy in man. Acta physiol. scand. 1954, 31, 1.

16. Goodall, McC., and Kirshner, N. Effect of cervicothoracic ganglionectomy on the adrenaline and noradrenaline content in the mammalian heart. J. clin. Invest. 1956, 35, 649.

17. Armstrong, M. D., McMillan, A., and Shaw, K. N. F. 3-Methoxy-4-hydroxy-D-mandelic acid, a urinary metabolite of norepinephrine. Biochim. biophys. Acta 1957, 25, 422.

18. Axelrod, J., Inscoe, J. K., Senoh, S., and Witkop, B. O-methylation, the principal pathway for the metabolism of epinephrine and norepinephrine in the rat. Biochim. biophys. Acta 1958, 27, 210.

19. Kirshner, N., Goodall, McC., and Rosen, L. Metabolism of dl-adrenaline-2- $\mathrm{C}^{\mathbf{1 4}}$ in the human. Proc. Soc. exp. Biol. (N. Y.) 1958, 98, 627.

20. Goodall, McC., Kirshner, N., and Rosen, I. Metah)olism of noradrenaline in the human. J. clin. Invest. $1959,38,707$.

21. Goodall, McC. Metabolic products of adrenaline and noradrenaline in human urine. Pharmacol. Rev. 1959, 11, 416.

22. von Euler, U. S., and Hellner, S. Excretion of noradrenaline, adrenaline, and hydroxytyramine in urine. Acta physiol. scand. 1951, 22, 161.

23. Hökfelt, B., and McLean, J. The adrenaline and noradrenaline content of the suprarenal glands of the rabbit under normal conditions and after various forms of stimulation. Acta physiol. scand. $1950,21,258$.

24. Holland, W. C., and Schümann, H. J. Formation of catechol amines during splanchnic stimulation of the adrenal gland of the cat. Brit. J. Pharmacol. 1956, 11, 449.

25. Bygdeman, S., and von Euler, U. S. Resynthesis of catechol hormones in the cat's adrenal medulla. Acta physiol. scand. 1958, 44, 375.

26. von Euler, U. S. The distribution of sympathin $\mathrm{N}$ and sympathin $\mathrm{A}$ in spleen and splenic nerves of cattle. Acta physiol. scand. 1949, 19, 207.

27. von Euler, U. S., and Hamberg, U. Colorimetric estimation of noradrenalin in the presence of adrenalin. Science 1949, 110, 561.

28. Goodall, McC., and Kirshner, N. Biosynthesis of adrenaline and noradrenaline in vitro. $\mathrm{J}$. biol. Chem. 1957, 226, 213.

29. Gurin, S., and Delluva, A. M. The biological synthesis of radioactive adrenaline from phenylalanine. J. biol. Chem. 1947, 170, 545.

30. Udenfriend, S., and Wyngaarden, J. B. Precursors of adrenal epinephrine and norepinephrine in vivo. Biochim. biophys. Acta 1956, 20, 48.
31. Kirshner, N., and Goodall, McC. The formation of adrenaline from noradrenaline. Biochim. biophys. Acta 1957, 24, 658.

32. Embden, G., and Kalberlah, F. Uber Acetonbildung in der Leber. Beitr. chem. Physiol. Path. 1906, 8, 121.

33. Edson, N. L. Ketogenesis-Antiketogenesis. II. Ketogenesie from amino-acids. Biochem. J. 1935, 29, 2498.

34. Jankelson, I. R. Free tyrosin in the blood filtrate as an indication of liver disease. Amer. J. dig. Dis. 1942, 9, 99.

35. Weinhouse, S., and Millington, R. H. Ketone body formation from tyrosine. J. biol. Chem. 1949, 181, 645.

36. Dunér, H. The influence of the blood glucose level on the secretion of adrenaline and noradrenaline from the suprarenal. Acta physiol. scand. 1953, 28, suppl. 102.

37. Garcia-Ramos, J., and Ramirez de Arellano, J. Los efectos de la adrenalina sobre el consumo de oxigeno del corazon. Arch. Inst. Cardiol. Méx. 1951, 21, 205.

38. Gollwitzer-Meier, K., Kramer, K., and Krüger, E. Die Wirkung des Adrenalins auf die Energetik des Herzens. Pflüg. Arch. ges. Physiol. 1936, 237, 639.

39. Lundholm, L. The effect of 1-noradrenaline and ergotamine on the oxygen consumption of guineapigs. Acta physiol. scand. 1949, 18, 341.

40. Thibault, O. Adrénaline et sympathine. Action de la nor-adrénaline sur la consommation d'oxygène du rat blanc. C. R. Soc. Biol. (Paris) 1948, 142, 47.

41. Barcroft, H., and Konzett, H. Action of noradrenaline and adrenaline on human heart-rate: Preliminary communication. Lancet 1949, 1, 147.

42. Collier, H. D., Meyers, F. H., and Schmitt, G. H. Effect of infusions of epinephrine and arterenol on the hemodynamics of normal and shocked dogs. Fed. Proc. 1955, 14, 328.

43. Nathanson, M. H., and Miller, H. The action of nor-epinphrine and of epinephrine on the ventricular rate of heart block. Amer. Heart J. 1950, 40, 374.

44. Barcroft, H., and Swan, H. J. C. Sympathetic Control of Human Blood Vessels. London, Arnold, 1953.

45. Folkow, B. Nervous control of the blood vessels. Physiol. Rev. 1955, 35, 629.

46. Goldenberg, M., Pines, K. L., Baldwin, E. D., Greene, D. G., and Roh, C. E. The hemodynamic response of man to nor-epinephrine and epinephrine and its relation to the problem of hypertension. Amer. J. Med. 1948, 5, 792.

47. Goodall, McC., and Long, M. Effect of whole-body $\mathrm{X}$-irradiation on the adrenal medulla and the hormones adrenaline and noradrenaline. Amer. J. Physiol. 1959, 197, 1265. 